\title{
Understanding Faculty Collaboration and Productivity: A Case Study
}

\author{
Chung-Yen $\mathrm{Yu}^{1}$, Yung-Ting Chuang ${ }^{2} \&$ Hsi-Peng Kuan ${ }^{2}$ \\ ${ }^{1}$ System Information Section, National Yang-Ming University Library, Taipei, Taiwan \\ ${ }^{2}$ Department of Information Management, National Chung Cheng University, Chia-Yi County, Taiwan \\ Correspondence: Yung-Ting Chuang, Department of Information Management, National Chung Cheng \\ University, Chia-Yi County, Taiwan. Tel: 886-5-2720411x24621. E-mail: ytchuang@mis.ccu.edu.tw
}

Received: December 6, 2016

Accepted: February 3, 2017

Online Published: February 9, 2017

doi:10.5539/ass.v13n3p1

URL: http://dx.doi.org/10.5539/ass.v13n3p1

\begin{abstract}
Research productivity has been always an important part of every academic's job, since it has a profound effect on faculty promotion and tenure decisions. In addition, some scholars believe that co-authorship between faculty members has a great impact on their academic life and faculty advancement. Since 2005, the Ministry of Education of Taiwan (MOE) has developed two university programs and evaluation policies for improving the competitiveness and internationalization of Taiwan universities, and has clearly stated that there is a strong relationship between faculty promotion and research performance. However, none of them has used social network analysis (SNA) to examine research productivity and co-authorship under two university programs and evaluation policies from MOE in Taiwan. Therefore, in this study, we first uses SNA to analyze the research productivity, collaboration patterns, and publication strategies of faculty members in a Management Information Systems (MIS) department at a national university in Taiwan. Then, we used D3, a well-known drawing tool to create data visualization using JavaScript libraries, to visualize and discuss how these two university programs and evaluation policies from the MOE affected these patterns and strategies. We hope that our study not only provides beneficial information to the MIS department, but can be treated as an important source for MOE committees in their future adjustment of university programs and policies.
\end{abstract}

Keywords: Social Network Analysis, D3, Co-authorship, Data Visualization, Research Collaboration Patterns and Networks, Research Productivity, Journal Publication

\section{Introduction}

Research productivity is a primary part of any academic's job (Jones et al., 1989; Salthouse et al., 1978), as it is a crucial influence on faculty promotion and tenure decisions. For this reason, some scholars have 1) measured the impact of faculty's research output (Albrecht et al., 2015); 2) analyzed the factors that affect the research productivity of production and operational management groups (Hadjinicola \& Soteriou, 2006); 3) discussed trends in senior faculty productivity over time (Bonzi, 1992); and 4) investigated the journal publications of MIS departments in Taiwan from 2001 to 2008 (Lai et al., 2011). In Taiwan, research productivity is also an important part of most universities. According to Chou (2014), the Ministry of Education of Taiwan (MOE) developed its Program for Promoting Academic Excellence in universities (PPAE), Aiming Top University \& Elite Research Center Development Plan (ATU Plan), and formal university evaluation policy in 2005, where the aim is to improve the competitiveness and internationalization of Taiwan universities. By having these two university programs and this evaluation policy, MOE established a strong relationship between faculty promotion and research performance in which research performance is evaluated based on impact factors and number of publications in SCI-, SCIE-, SSCI-, TSSCI-, and A\&HCI-indexed journals. Because of this, many departments established recommended journal lists (henceforth referred to as A-lists) for faculty promotion purposes. Similarly, the Ministry of Science and Technology of Taiwan (MOST) also published recommended journal lists (henceforth called MOST lists) for several categories (e.g. recommended journal lists from the Information Science \& Library Science category (Liang, 2013)), which encourage Taiwanese scholars to submit their papers to the recommended journals in their field in order to get more research funding. Because of the above reasons, Asian scholars put much more effort into their research productivity than do their Western colleagues (Horta \& Jung, 2014).

In addition, some scholars believe that co-authorship between faculty members (e.g., writing research project 
proposals, conducting research projects, or writing conference/journal papers) is important, and has a great impact on their academic life and faculty advancement. Knowing the significant impact on co-authorship, Fox and Faver (1984) conducted semi-structured in-depth interviews with a few social scientists, and discussed the advantages, disadvantages, and motivations of collaboration based on the points of view of social scientists. In addition, other scholars measured: 1) the patterns of scientific collaboration in bibliographic databases in biology, physics, and mathematics (Newman, 2004); 2) differences in collaboration experiences across different disciplines (Tsai et al., 2016); 3) the evolution of collaboration in multi-authored publications from the Physical Review journals database (Wardil \& Hauert, 2015); 4) patterns of scientific collaboration in tourism research (Benckendorff \& Zehrer, 2014); 5) scholarly influence, scientific collaboration, antecedents to co-authorship, and effect of co-authorship in five leading Information Systems (IS) journals (Gallivan \& Ahuja, 2015); characteristics and patterns in the field of additive manufacturing (Zhang et al., 2016); 6) examining whether international collaboration is beneficial in biochemical research (Sud \& Thelwall, 2016); and 7) discussing the good and bad of research collaborations across a range of scientific and engineering disciplines (Bozeman et al., 2015).

Most of the work mentioned above analyzed the collaboration or research productivity patterns in an academic discipline, but none of them examined how the two university programs and evaluation policy established by the MOE affected research productivity and co-authorship in Taiwan. As mentioned previously, MOE established two university programs and an evaluation policy for increasing the internationalization of Taiwan universities in 2005 , and therefore, it is important that one study can investigate whether these two university programs and this evaluation policy affects faculty members' collaboration and productivity patterns. Moreover, Li et al. (2013) and Burt et al. (2013) both also observe that social network analysis (SNA) is an effective way to analyze collaborative research papers. Therefore, in this paper, we first used SNA to analyze the research productivity, collaboration patterns, and publication strategies from a Management Information Systems (MIS) department at a national university in Taiwan. Then, we apply D3 (2016), a well-known drawing tool to create data visualization using JavaScript libraries, to visualize how the two university programs and the evaluation policy affect faculty collaboration, research productivity, and publication strategies in an MIS department at a national university in Taiwan (henceforth known as MISU). In our paper, we consider the following questions:

Q1. Do faculty members tend to publish papers alone? Or do they tend to publish co-authored papers with others?

Q2. Do faculty collaboration patterns change with respect to their academic positions?

Q3. Do senior faculty members tend to collaborate with other junior faculty?

Q4. Do faculty members tend to collaborate with others within or across Taiwan?

Q5. Do these two university programs and evaluation policy from MOE affects the collaboration patterns?

Q6. Do faculty members place more emphasis on publishing more "quality" or "quantity" papers?

Q7. Do these two university programs and this evaluation policy from the MOE affect research productivity patterns?

Q8. What are the publication strategies among these MIS faculty?

Q9. Are the publication strategies related to the recommended journal lists (e.g. MOST or A-list)?

On the other hand, we applied SNA and D3 to study the visualize the following: 1) the evolution of MIS faculty collaboration patterns; 2) collaboration patterns with others within or across Taiwan; 3) collaboration patterns according to faculty academic positions; 4) collaboration patterns after MOE introduced its two university programs and its evaluation policy; 5) research productivity patterns among MIS faculty; 6) research productivity patterns of senior faculty members; 7) research productivity strategies after the MOE introduced these two university programs and this evaluation policy; 8) publication strategies after the MOST and A-lists were created. After obtaining all of the analysis, we concluded our observations on collaboration patterns, research productivity, and publication strategies. We believe that these observations can provide initial guidance to MIS faculty members for their future faculty advancement and tenure decisions. In addition, we believe that our study can be treated as an important resource for the MOE committees for future adjustments/improvements on university programs and the evaluation policy.

The remainder of this paper is organized as follows. Section 2 of this paper discusses related work, and Section 3 describes how we collected and analyzed our data. Section 4 provides the visualization of our data. In Section 5, we provide some discussion, followed by the conclusion and recommendations. In Section 6, we discuss the limitations and future work. 


\section{Related Work}

In this section, we discuss some relevant work, which addresses: 1) social network analysis, 2) knowledge maps and their application, 3) information graphics and data visualization

\subsection{Social Network Analysis}

The study of social networks has been developed to analyze social relations, and has been widely applied to several real-life scenarios. By definition, a social network is a social structure composed of social actors, dyadic ties, and social relationships among social actors (Liu et al., 2015). Social network analysis (SNA) first connects the relationships between social actors, where these social actors may be referred to individuals, organizations or family (Scott, 2002). Next, SNA analyzes the behavior of their social network activities with organizations, interpersonal relationships, partnerships, etc. (McAndrew \& Everett, 2015). According to Wasserman \& Faust (1994), SNA is an integration of social theory, observational studies, mathematical statistics, graphics, and other scientific disciplines. Some papers have adapted SNA to study the bibliometric co-authorship network (Zhang et al., 2014; Mena-Chalco et al., 2014), relationship between music writers and their partnerships (McAndrew \& Everett, 2015), and the relationships among social platforms such as Facebook or Twitter. Similarly, in this paper, we also apply SNA to analyze faculty members' research productivity, collaboration, and publication strategies.

\subsection{Knowledge Maps and Their Application}

Yoon et al. (2010) state that because of the rapid growth of knowledge creation, knowledge maps are an important research tool for successful knowledge management, and have been widely applied in bibliometrics, scientometrics, and other informatics fields (Xiao et al., 2013). Knowledge maps allow people to visualize data that displays the progress, structural relationships, or pattern flow of scientific knowledge (Chen \& Liu, 2005). Since knowledge maps can describe the relationships between nodes, they are often combined with social networks to investigate and analyze data. Recently, knowledge maps have been applied to several fields, mostly library and information science and bibliometrics. Most research uses UCINET, Bibexcel, or Citespace to create knowledge maps. The six types of knowledge maps include: 1) Two Dimensional Scientometric Map (2DSM); 2) Three-Dimensional Configuration Map (3DCM); 3) Multi-Dimensional Scaling Map (MDSM); 4) Self-Organizing Map (SOMP); 5) Social Network Analysis Map (SNAM); and 6) Path Finder Network Scaling Map (PFNET). In this paper, we apply social network analysis maps (SNAM) and path finder network scaling map (PFNET) to describe the collaboration between faculty members for our study.

\subsection{Information Graphics and Data Visualization}

Traditional data visualizations were originally taken from statistical graphics, and are related to information graphics, visual design, etc. According to Ware (2012), data visualization can be classified into four types: 1) temporal data visualization, 2) hierarchical and network structural data visualization, 3) text and cross-media data visualization, and 4) multivariate data visualization. However, with the high multi-dimensionality and massive quantities of data now in circulation, these traditional data visualizations cannot handle such high loads of information. Therefore, modern data visualization would need to handle the following characteristics: 1) able to analyze specific data, 2) has enough spatial distribution, 3) can offer high-dimensional display. Some of the well-known data visualization drawing tools which try to solve the above characteristics are: 1) D3, 2) Bibexcel, 3) CiteSpace, 4) TDA, and 5) Ucinet. Since our study focuses on relationships and collaboration between authors, we apply gravimetric maps and CSS from D3 for our experiment.

\section{Data Collection and Foundations}

In order to examine faculty collaboration and research productivity, we conducted an experiment that analyzed all the faculty members from an MIS Department at a national university in Taiwan (which we will call MISU). We first retrieved our data from the Ministry of Science and Technology of Taiwan (MOST), Journal Citation Reports (JCR), Web of Science (WOS), Google Scholar, and Google. There were total of 16 faculty members in MISU, 5 of them listed as professors, 4 as associate professors, and 7 as assistant professors. Among these faculty members, 11 were male and 5 were female. A total of 10 professors obtained their $\mathrm{PhD}$ degrees in the United States, 1 obtained a PhD degree in the United Kingdom, 1 obtained a PhD degree in New Zealand, and 4 obtained $\mathrm{PhD}$ degrees in Taiwan. Since our study only focuses on analyzing faculty collaboration and productivity based on journal publications, we filtered out the conference papers from their publication lists. After we finished collecting and cleaning data from these websites, we organized the data into the following five relational tables: 1) authors and articles table; 2) authors and periodicals table; 3) articles and years table; 4) authors and universities table; 5) articles and periodical table. After creating all five relational tables, we converted the data to the D3 format, and finally used D3 to present the final results. The steps of information 
retrieval, information processing, and information presentation are described in Figure 1, and the detailed steps are described in the following subsections.

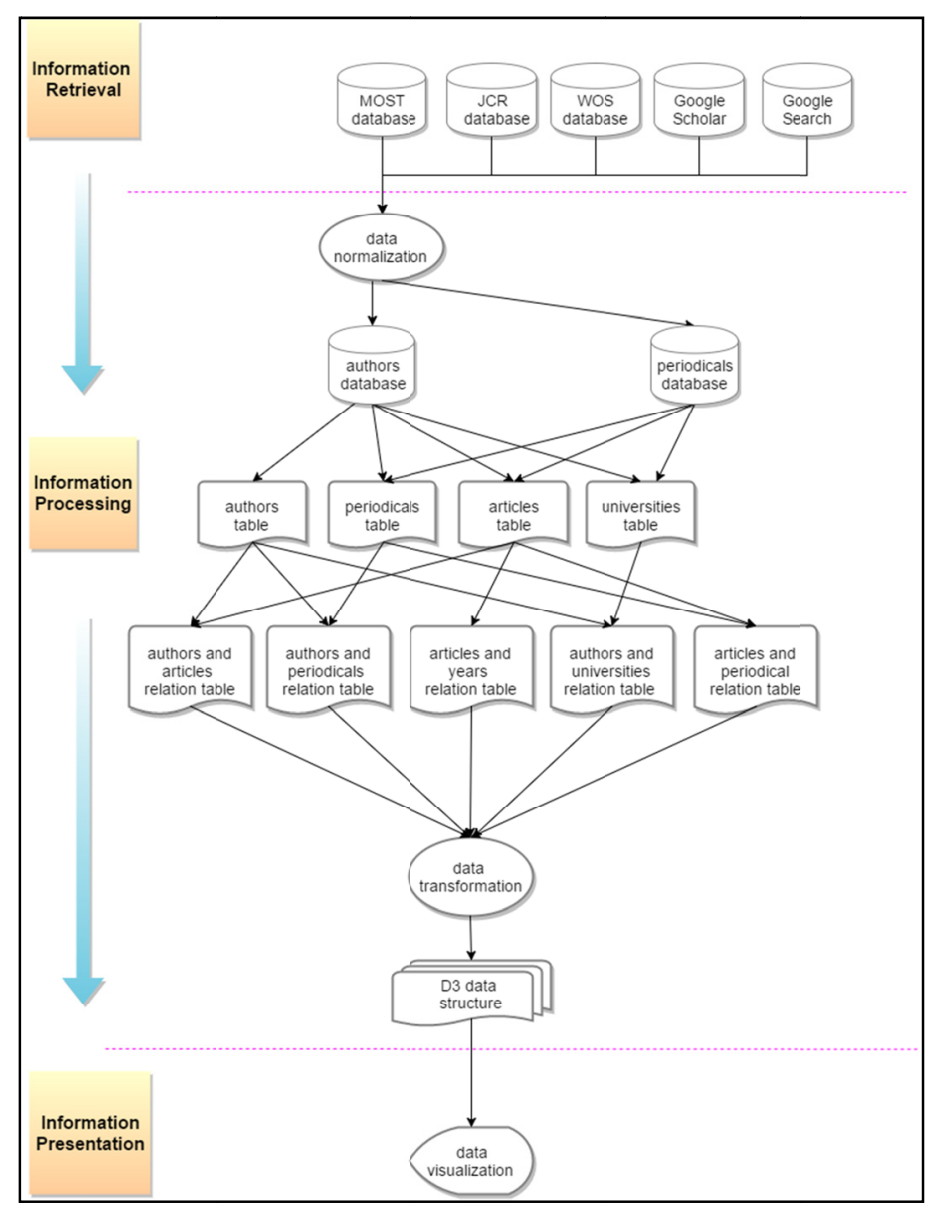

Figure 1. System Flow Diagram

\subsection{Information Retrieval}

Our data was first retrieved data from: 1) the Ministry of Science and Technology of Taiwan (MOST) website, 2) the Journal Citation Reports (JCR) website, 3) the Web of Science (WOS) website, 4) the Google Scholar website, and 5) Google. There were total of 393 journal articles published in MISU from 1992 to 2016. After we eliminated duplications, we had 378 publications left. Based on these 378 journal publications, we discovered that the MISU faculty members had collaborated with $133 \mathrm{MISU}$ PhD/MS students, 215 people (including both faculty members and students) from other institutions in Taiwan, and 33 faculty members from other countries. From these statistics, we can see that the MISU faculty members tend to collaborate with others in Taiwan, but not with others across countries. For journal indexing, we referred to SCI/SSCI information from the JCR website in 2014 and TSSCI information from the MOST website in 2015. After we finished the duplication process, we separated the data into the following attributes: 1) year; 2) article title; 3) author; 4) periodical title; and 5) abstracting and indexing.

\subsection{Information Processing}

We normalized the data after gathering all of it. Since some of the information huddled together into one column, we normalized and placed them the correct columns. Next, we fixed the abbreviation problems for the authors and journal titles that were listed in an abbreviation format. For some mistyped information (e.g. author names, article titles), we fixed them according to the Web of Science (WOS) website. Third, we de-duped the data that were displayed more than once. Fourth, we separated the cleaned data into two databases: 1) authors database; 2) periodicals database. Fifth, we applied these two databases and further created four tables: 1) authors table; 2) periodicals table; 3 ) articles table; 4) universities table. Furthermore, we applied these four tables and created the following five relational tables: 1) authors and articles table; 2) authors and periodicals table; 3 ) articles and years table; 4) authors and universities table; 5) articles and periodical table. 


\subsection{Information Presentation}

After we had completed the steps from Section 3.2, we next calculated the following: 1) contribution score; 2) year score; 3) degree centrality score. After all of the calculation values, we drew our graphs using D3, a well-known drawing tool to create data visualization using JavaScript libraries (Scott, 2012). D3 was created by Mike Bobstock (2016) as one of many open-source projects produced with other developers, and is released under the-three clause BSD license. D3 allows developers to use, fix, or place codes for business- or non-business-related purposes without any cost. We use gravimetric maps and CSS to create interactive web pages that show text functionality. The calculations used in D3 were described in the following sub-sections.

\subsubsection{Contribution Score}

Before calculating the contribution score, we retrieved the following attributes from our periodicals database: 1) journal ID; 2) abstracting and indexing; 3) impact factor; 4) journal ranking; 5) ISSN. Next, we identified the orders of authors, and set placement $=1$ if there was only one author in the article. Since several works believed that the first author is usually the person who has taken the most responsibility and work (Reisenberg \& Lundberg, 1990; Kennedy, 2003; Rennie et al., 1997; Mattsson et al., 2011), we placed more weight to the first author when there were more than one authors contained in an article. The placement is thus calculated as below:

$$
\text { Placement }= \begin{cases}0.5, & 1 \text { st author } \\ \frac{0.5}{n-1}, & \text { others }\end{cases}
$$

For example, if there were four authors (author A, author B, author C, and author D), and author A was the first author, then the placement for author $\mathrm{A}$ was 0.5 , and the places for author $\mathrm{B}$, author $\mathrm{C}$, and author $\mathrm{D}$ were all equals $0.5 /(4-1)=0.167$. After that, we calculated our journal rank according to the following table:

Table 1. Journal Ranking with corresponding score

\begin{tabular}{cccccc}
\hline Quartile in Category & Q1 & Q2 & Q3 & Q4 & Other \\
\hline Rank & 4 & 3 & 2 & 1 & 0 \\
\hline
\end{tabular}

For example, if an author published an article that belonged to Q1, then this author got score $=4$. Finally, we calculated our contribution score as follows:

$$
\text { Contribution }=\text { Placement } * \text { Rank }
$$

For example, if an author had a placement score $=0.5$, and the journal belonged to Q2, then this author would get final contribution $=0.5 * 3=1.5$.

\subsubsection{Contribution Score with EWMA}

In order to calculate and present the evolution of the faculty collaboration and research productivity, our study further adapted Exponential Weighted Moving Average (EWMA) to calculate the contribution score with respect to the publication year. In short, EWMA is an algorithm that orders elements according to time, and places the weights according to recency (i.e., it places the highest weight on the most recent element, and lowest weight on the least recent element). For example, articles published in 2016 would have higher weights compared to articles published in 2015, and articles published in 2015 would have higher weights compared to articles published in 2014, and so on. We calculated our contribution score using EWMA as follows:

$$
\text { Contribution_EWMA }_{\mathrm{t}}=\left\{\begin{aligned}
\text { Contribution }_{1}, & t=1 \\
\mathrm{c} \times \text { Contribution }_{\mathrm{t}}+(1-\mathrm{c}) \text { Contribution_EWMA }_{\mathrm{t}-1,} & t>1
\end{aligned}\right.
$$

Where:

$$
\text { - } \quad \text { : the smoothing factor, } 0<=\mathrm{c}<=1
$$

- Contribution_EWMA $\mathrm{E}_{\mathrm{t}}$ : the output of the contribution score with EWMA at time $\mathrm{t}$

- Contribution : the current contribution score

For example, if $\mathrm{c}=0.97$, and an author A published one paper as a first author in 2015, and published another paper as a first author in 2016, then the total contribution score with EWMA would be $=0.5+0.5 * 0.97=$ 0.985 .

\subsubsection{Degree Centrality Score}

In order to visualize and capture the collaboration and productivity of the faculty network, we used three network centralities (Newman, 2004) to examine the most important nodes in the faculty network: 1) degree 
centrality; 2) betweenness centrality; 3) closeness centrality. We describe each centrality in the below paragraphs.

\section{Degree Centrality}

Degree centrality is a simplest way to measure the most important or central nodes in a network, where it basically measures the number of neighbors of each node. A node with a high degree of centrality is likely to be important since it might: 1) have more influence on several nodes in the network, 2) help spread information in the network faster, 3) obtain more reputation than other nodes that have fewer neighbors. The calculation of degree centrality is described below:

$$
\mathrm{C}_{\mathrm{D}}=\frac{\sum_{i=1}^{g}\left[\mathrm{C}_{\mathrm{D}}\left(\mathrm{n}^{*}\right)-\mathrm{C}_{\mathrm{D}}(\mathrm{i})\right]}{[(\mathrm{N}-1)(\mathrm{N}-2)]}
$$

where:

- $\mathrm{C}_{\mathrm{D}}\left(\mathrm{n}^{*}\right)$ : the maximum connections in the network

- $\mathrm{N}$ : the total number of nodes in the network

For example, Figure 2 shows that the central node has the largest radius, since it has several connections to five other nodes. Other nodes only have one connection to the central node. Therefore, the $\mathrm{C}_{\mathrm{D}}$ for the central node would be:

$$
C_{D}=\frac{(5-1)+(5-2)+(5-3)+(5-4)+(5-5)}{(6-1)(6-2)}=1
$$

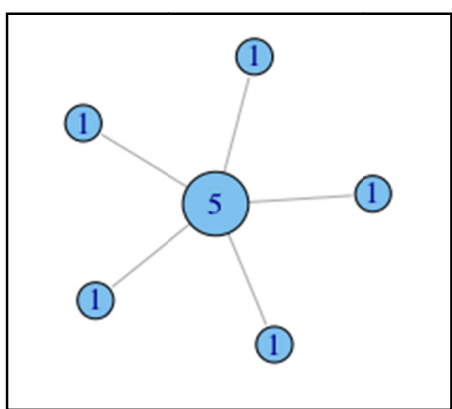

Figure 2. Example of Degree Centrality. Source: Mascolo (2012)

The range of $C_{D}$ is between 0 and 1 . When the value of $C_{D}$ is closer to 1 , it means the node has a higher degree of centrality plus higher connections to other nodes. Therefore, we use a similar strategy to measure the collaboration between faculty members, such that when a faculty member has many collaborations with others, he/she would have a higher degree of centrality value in the network.

\section{Closeness Centrality}

Closeness centrality is a way to measure the average distance from a node to other nodes. A node with high closeness centrality has shorter distance to other nodes, and therefore, it would have quicker access to the other information, to stop epidemics or to influence other nodes in the network. The calculation of closeness centrality is described below:

$$
C_{C}=\left[\frac{\sum_{j=1}^{N} d\left(C_{C}(i), j\right)}{N-1}\right]^{-1}
$$

where:

- $\mathrm{d}\left(\mathrm{C}_{\mathrm{C}}(\mathrm{i}), \mathrm{j}\right)$ : the distance between current node $\left(\mathrm{C}_{\mathrm{C}}(\mathrm{i})\right)$ and $\mathrm{j}$

- $\quad \mathrm{N}$ : the total number of nodes in the network

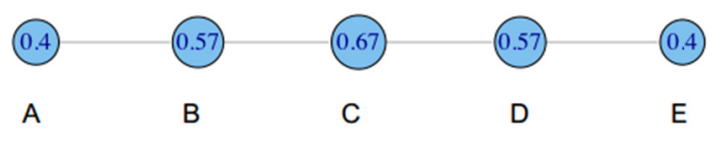

Figure 3. Example of Closeness Centrality. Source: Mascolo (2012) 
Figure 3 shows the example of a weightless network, where all the edges among all nodes have weight $=1$. Therefore, the distance between node A and node B is 1 , between node $\mathrm{A}$ and node $\mathrm{C}$ is 2 , between node $\mathrm{A}$ and node $\mathrm{D}$ is 3 , and between node $\mathrm{A}$ and node $\mathrm{E}$ is 4 . Therefore, the closeness centrality of node $\mathrm{A}$ will be:

\section{Betweenness Centrality}

$$
C_{C}=\left[\frac{\sum_{j=1}^{N} d(A, j)}{N-1}\right]^{-1}=\left[\frac{1+2+3+4}{5-1}\right]^{-1}=0.4
$$

In a network, there is at least one shortest path between two nodes, and betweenness centrality measures the number of times that a node lies on the shortest path between other nodes. A node with high betweenness centrality is very important, since it has the power to control the information passing between others. In addition, these are the nodes that might disable the communications between other nodes if they are offline. The importance of knowing betweenness centrality is that we can have a better idea to further help protect the network from breaking into several disconnected subnetworks. The calculation of betweenness centrality is explained below:

where:

$$
\mathrm{C}_{\mathrm{B}}=\frac{\mathrm{C}_{\mathrm{B}}(\mathrm{i})}{[(\mathrm{n}-1)(\mathrm{n}-2) / 2]}
$$

\section{- $\quad[(n-1)(n-2) / 2]:$ the number of pairs of edges except the node itself}

Figure 4 shows an example of a betweenness centrality where each node has a number indicating the number of nodes that will get through it. For example, node $\mathrm{C}$ lies between node $\mathrm{A}$ and node $\mathrm{D}$, node $\mathrm{A}$ and node $\mathrm{E}$, node $\mathrm{B}$ and node $\mathrm{D}$, and node $\mathrm{B}$ and node $\mathrm{E}$; therefore, $\mathrm{C}$ has value $=4$. Node $\mathrm{B}$ lies between node $\mathrm{A}$ and node $\mathrm{C}$, node $\mathrm{A}$ and node $\mathrm{D}$, and node $\mathrm{A}$ and node $\mathrm{E}$; therefore $\mathrm{B}$ 's value $=3$. Node A does not connect any other pairs of nodes, so it has a value of 0 . From this figure, we can see that $\mathrm{C}$ has the largest value, and therefore $\mathrm{C}$ is the most important node in this network.

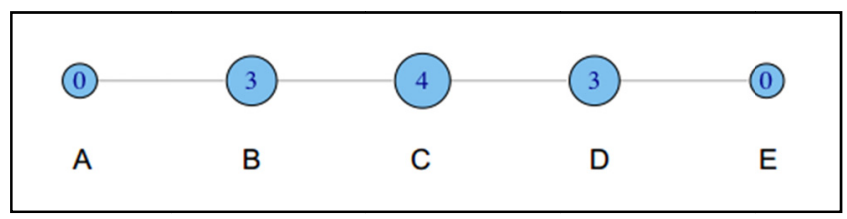

Figure 4. Example of Betweenness Centrality. Source: Mascolo (2012)

\section{Data Analysis}

In this section, we first presented our graphs using D3. When considering faculty collaboration, we treated each node as a professor, and each edge as the collaboration between two professors. The radius of a node represents as the total publications of a particular professor; therefore, a professor with more publications gets a larger radius. On the other hand, the width of the edge represents as the number of collaborations between two professors. The thicker the line is, the more collaborations between these two professors. In the rest of this section, we discussed and analyzed the following: 1) faculty collaboration; 2) research productivity; 3) publication strategies; and 4) evolution of faculty collaboration and research productivity.

\subsection{Faculty Collaboration}

\subsubsection{Degree Centrality}

Figure 5 shows the degree centrality of the faculty collaboration of MISU. In this figure, red colors correspond to the professors, blue colors correspond to the associate professors, orange colors correspond to the assistant professors, and light blue colors correspond to others. From this figure, we can observe that C86 was the most important node in the network, as this professor had high collaboration and research productivity with others. In addition, C86 had direct collaborations with six other professors, and these six professors had collaborated with five other professors, which formed a large sub-network in this figure. On the other hand, there were four disconnected sub-networks in this figure, which were: 1) the sub-network from $\mathrm{C} 277,2$ ) the sub-network from $\mathrm{C} 50,3)$ the sub-network from C232, and 4) the sub-network from C41. The interesting fact was that C277, C50, $\mathrm{C} 232$, and $\mathrm{C} 41$ were all assistant professors. One possible reason might be that these professors were new to MISU, and therefore they had not yet established long-term collaborations with other MISU professors. In addition, C277, C50, and C232 had collaborated with their students or other professors outside from MISU. On the other hand, we noticed that $\mathrm{C} 41$ had not had any collaboration with anyone, and tended to publish papers independently; thus, it was hard to visualize this faculty member in this figure. Therefore, we can further 
conclude that the two university programs and evaluation policy from MOE had influenced most of the faculty in MISU to publish co-authored papers.

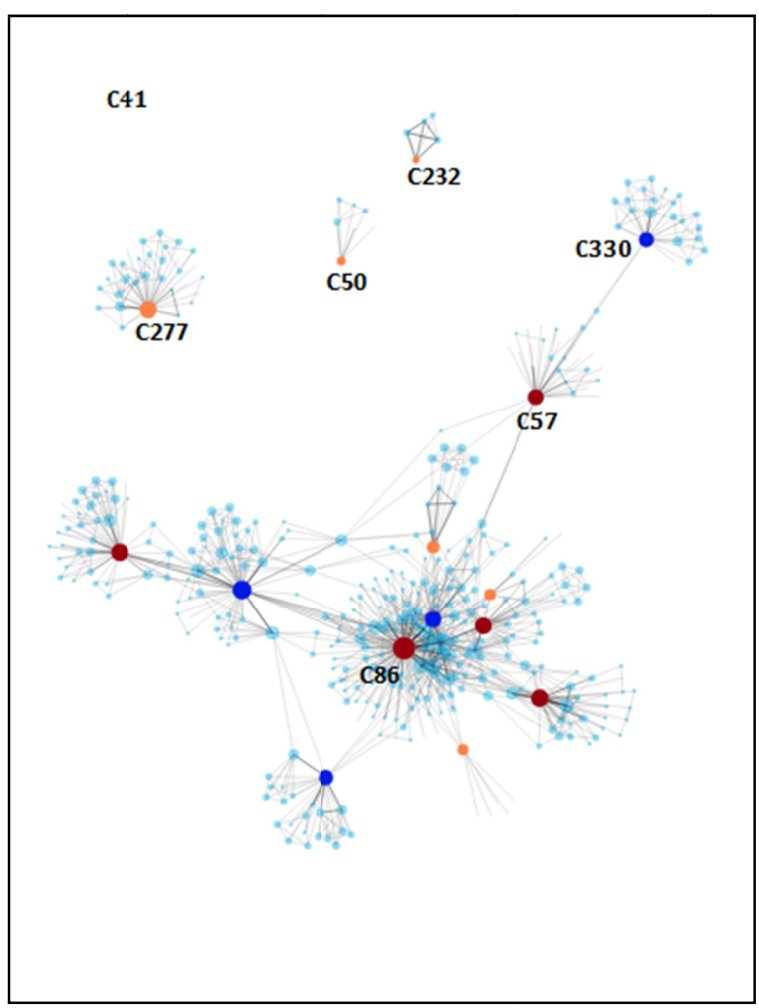

Figure 5. Degree Centrality of MISU

\subsubsection{Betweenness Centrality}

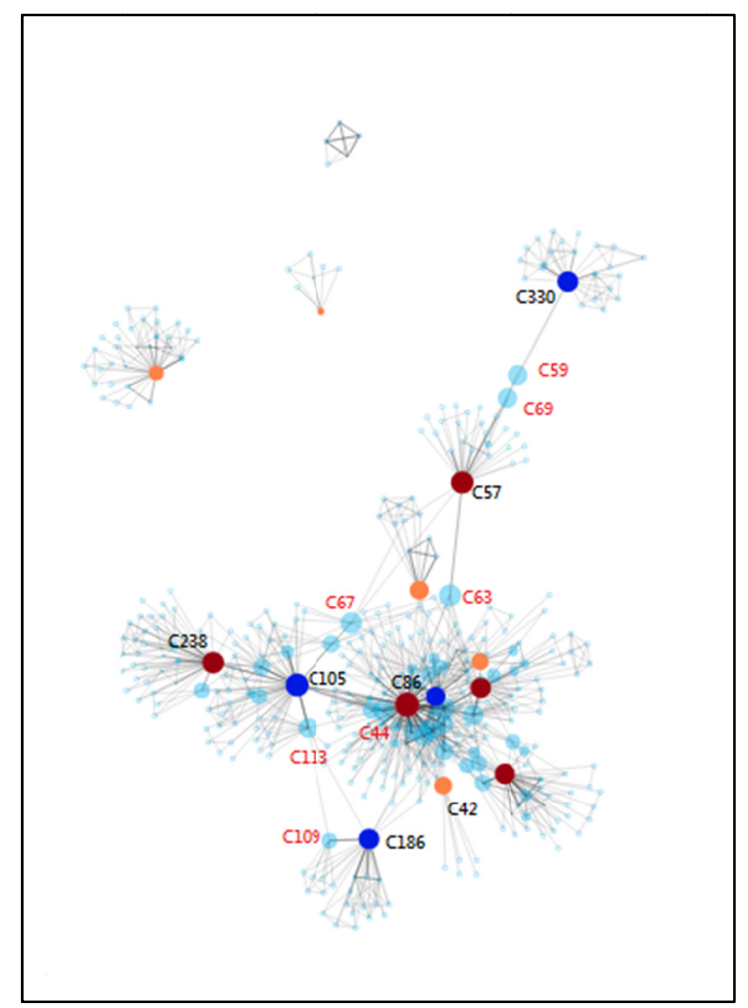

Figure 6. Betweenness Centrality of MISU

Figure 6 shows the betweenness centrality of MISU faculty. As we saw from this figure, almost all professors had important roles in this network. In addition, we noticed that some non-MISU professors (indicated in light 
blue colors) acted as bridges to connect the MISU network. Moreover, we observed five important nodes in the network: 1) C59, because it was the only way to get to C330;2) C69, because it was the only way to get to C59 and $\mathrm{C} 330$; 3) C57, because it was the only way to get to C69, C59, and C330; 4) C63, because it was the only way to get through $\mathrm{C} 57, \mathrm{C} 69, \mathrm{C} 59$, and C330; and 5) C105, because it was the only way to get to C238. Among these five important nodes, only two were MISU professors. This was an interesting since professors outside of MISU can still act as important nodes in the MISU network. Furthermore, C59, C69, C57, C63, and C105 all acted as important bridges in this MISU network, such that all communication from both C330 and C238 sub-networks would be disabled if they were gone.

Figure 7 shows the enlarged view of Figure 6, where we emphasized the surrounding of C86. First, we saw that C33 had a high productivity, and high collaboration with C86. In addition, we observed that C1 did not collaborate with $\mathrm{C} 86$ directly, but was connected with $\mathrm{C} 86$ via $\mathrm{C} 33$. Moreover, C42 did not have direct collaboration with $\mathrm{C} 86$, but was indirectly connected with $\mathrm{C} 86$ via C33. Therefore, we spotted that even though C33 was not a faculty member in MISU, it still played an important role in MISU. On the other hand, we noticed that C25 was another important node since it acted as an important bridge for C1, C205, and C63. Similarly, we observed that $\mathrm{C} 18$ was important since it was the bridge to connect $\mathrm{C} 1$ and $\mathrm{C} 105$, and $\mathrm{C} 44$ was important since it was the bridge connecting $\mathrm{C} 42$ and $\mathrm{C} 105$. We can conclude that even though there were few collaborations with other faculty outside of the country, these faculty still had important roles in MISU network.

\subsubsection{Closeness Centrality}

Figure 8 shows the closeness centrality of MISU. As we noticed from the figure, the central red node C 86 has the highest closeness centrality, and therefore, it has been placed toward the center of the larger sub-network. Next, as we further observed from this figure, when a node was farther from the center of the network (e.g., C330, C42, C186, C136, C238, etc.), the radius got smaller (e.g. C330 has a smaller radius compared to C57). On the other hand, when a node was closer to the center of the network and had a larger radius (e.g. C86, C115, C205, C105, $\mathrm{C} 1$ ), it had a greater chance to influence or spread information in the network.

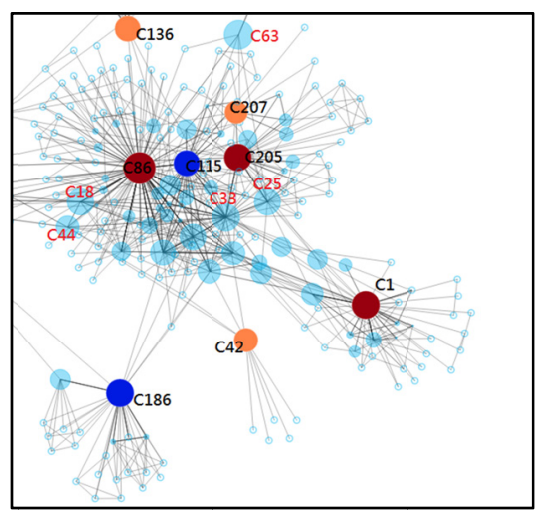

Figure 7. Enlarged View of Figure 6

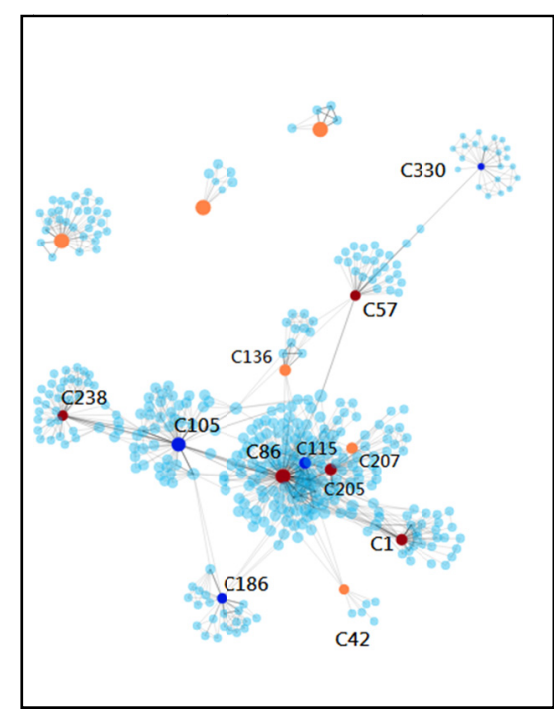

Figure 8. Closeness Centrality of MISU 


\subsubsection{Power-Law Degree Distribution of Faculty Collaboration}

Figure 9 shows the power-law degree distribution of faculty collaboration. The x-axis shows the number of faculty collaborations, and the y-axis shows the frequency. As we noticed from the figure, the faculty collaboration followed the power-law degree distribution (Jeong et al., 2000, 2001), also called a scale-free network. In this figure, there were only a few faculty members that had high collaboration with others (e.g. more than 28 collaborations), and most of the faculty members had fewer than 10 collaborations with others.

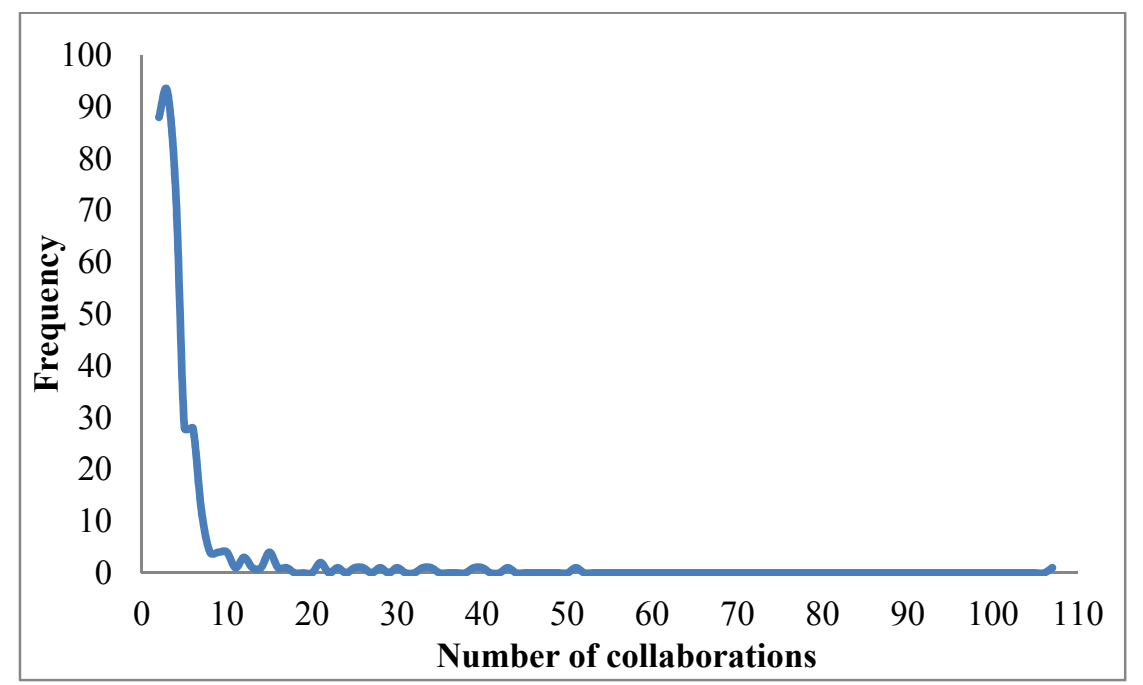

Figure 9. Power-Law of Faculty Collaboration

\subsection{Research Productivity}

Table 2. Rank of Contribution Score, Placement Score, and Rank Score

\begin{tabular}{cccc}
\hline Rank & Placement Score & Rank Score & Contribution Score \\
\hline 1 & $\mathrm{C} 86$ & $\mathrm{C} 86$ & $\mathrm{C} 330$ \\
2 & $\mathrm{C} 330$ & $\mathrm{C} 57$ & $\mathrm{C} 57$ \\
3 & $\mathrm{C} 57$ & $\mathrm{C} 330$ & $\mathrm{C} 86$ \\
4 & $\mathrm{C} 1$ & $\mathrm{C} 105$ & $\mathrm{C} 1$ \\
5 & $\mathrm{C} 277$ & $\mathrm{C} 1$ & $\mathrm{C} 105$ \\
6 & $\mathrm{C} 238$ & $\mathrm{C} 205$ & $\mathrm{C} 205$ \\
7 & $\mathrm{C} 105$ & $\mathrm{C} 238$ & $\mathrm{C} 41$ \\
8 & $\mathrm{C} 115$ & $\mathrm{C} 115$ & $\mathrm{C} 238$ \\
9 & $\mathrm{C} 205$ & $\mathrm{C} 41$ & $\mathrm{C} 115$ \\
10 & $\mathrm{C} 232$ & $\mathrm{C} 186$ & $\mathrm{C} 50$ \\
11 & $\mathrm{C} 41$ & $\mathrm{C} 50$ & $\mathrm{C} 42$ \\
12 & $\mathrm{C} 50$ & $\mathrm{C} 42$ & $\mathrm{C} 232$ \\
13 & $\mathrm{C} 186$ & $\mathrm{C} 232$ & $\mathrm{C} 186$ \\
14 & $\mathrm{C} 42$ & $\mathrm{C} 207$ & $\mathrm{C} 207$ \\
15 & $\mathrm{C} 207$ & $\mathrm{C} 277$ & $\mathrm{C} 277$ \\
16 & $\mathrm{C} 136$ & $\mathrm{C} 136$ & $\mathrm{C} 136$ \\
\hline
\end{tabular}

Table 2 shows the place score, rank score, and contribution score for the 16 faculty members in the MISU network, as their calculations were all described in Section 3.3.1. In the placement score column, we noticed that C86 was ranked first (Placement=40.5833), C330 is second (Placement=31.0417), C57 is third (Placement=21.6667), $\mathrm{C} 1$ is fourth (Placement=15.0833) and C277 is fifth (Placement=14.2917). In addition, as noticed that from these calculation, C86, C330, and C57 were all MISU professors, and they were the first author in most of their publications. On the other hand, $\mathrm{C} 1$ and $\mathrm{C} 277$ had slightly lower values than $\mathrm{C} 86, \mathrm{C} 330$, and C57, and this might be due to the fact that most of their work was attributed to them as second or third author.

In the rank score column, we can see that the first professor, with the highest score, is C86 (Rank=117), followed by C57 (Rank=99), C330 (Rank=86), C105 (Rank=72), and C33 (Rank=68). Besides C33, the other four were MISU professors. Comparing both placement score and rank column, we observed that C57 was in second place in rank score, but third in placement score. This indicated that C57 was not the first author of some of his/her 
work, yet these works were published in the top quartiles in the journal category (Q1/Q2 journal). Nonetheless, C86, C57, and C330 still remain the top three in both placement score and rank score, and therefore, these told us that the publications of these three professors are all of high quality and quantity.

The contribution-score column shows the top ten professors as follows: 1) C330, 2) C57, 3) C86, 4) C1, 5) C105, 6) $\mathrm{C} 205$, 7) C41, 8) C238, 9) C115, and 10) C50. Except for C33, all were MISU faculty. In Table 2, we spotted that $\mathrm{C} 86, \mathrm{C} 330$, and $\mathrm{C} 57$ reside in the top three ranks among these three categories. In addition, we noticed that C86 often submitted work in the Journal of Information Management, Decision Support Systems, and Information \& Management; C330 often published in International Journal of Neural Systems and Clinical EEG and Neuroscience; C57 often published work in Decision Support Systems and Information \& Management.

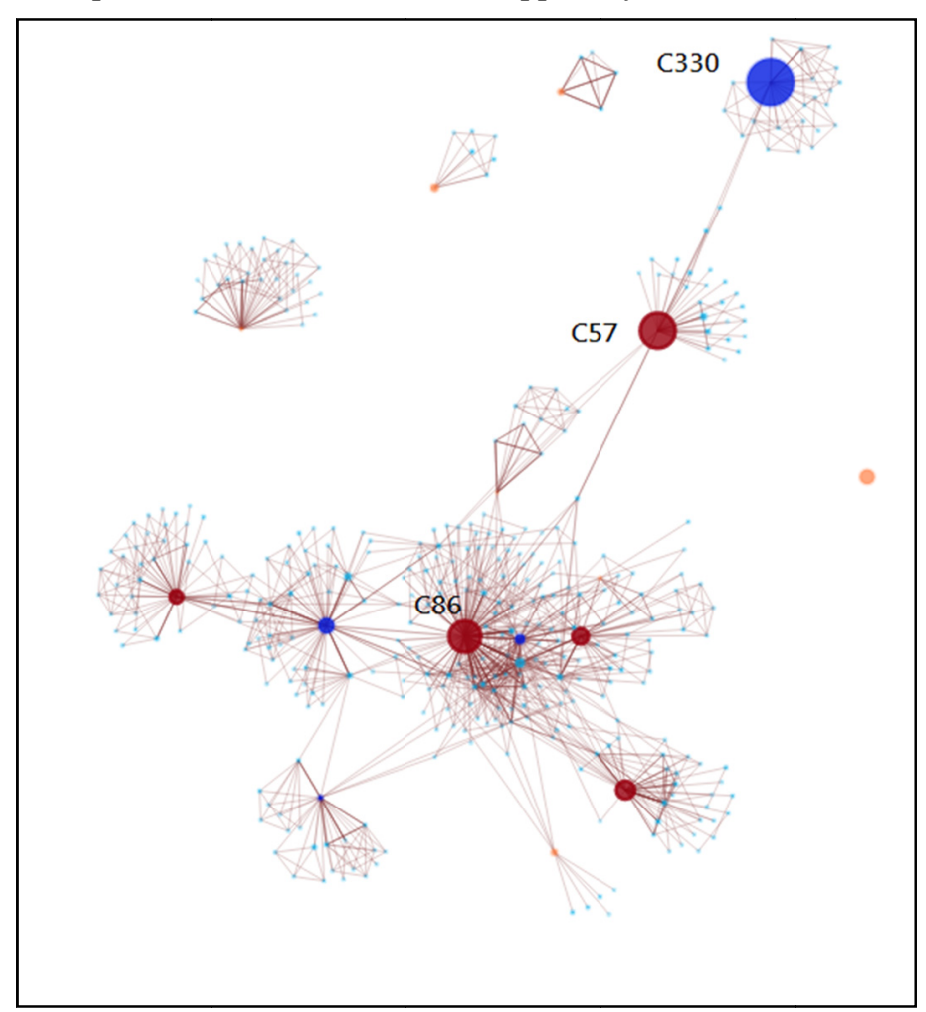

Figure 10. Contribution Score of MISU

Figure 10 shows the contribution scores of the MISU network. Comparing this figure with Figure 5, we noticed that C330, C57, and C86 were all significantly higher in Figure 10, when considering the contribution score rather than the total number of publications. This confirmed that the two university programs and evaluation policy from MOE had influenced faculty not only to focus on publishing "high-quantity" papers, but also to publish "high-quality" papers, as C330, C57, and C86 were notable examples.

\subsection{Publication Strategies}

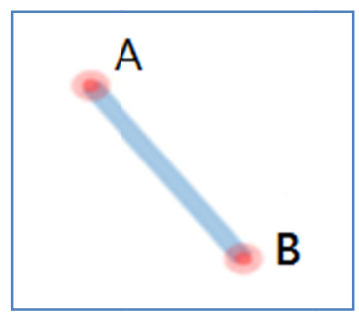

Figure 11. Example of Journal A and Journal B Submission Pattern

In this section, we analyzed the journal titles in Information Science \& Library Science category from the recommended journal list from both MOST (Liang, 2013; see Appendix 1) and MISU's promotion-recommended journal list (see Appendix 2). When considering the journal publication patterns, we treated each node as a journal, and each edge between two nodes as the number of times that a professor had publications in both journals. If there is a thicker edge between two nodes, that means there were several 
professors that had published their work in both journals. The radius of a node represents the total publications of a particular journal; therefore, if several professors published in a particular journal, it would get a larger radius. For example, Figure 11 means that there were several professors that had previously published their work in both Journal A and Journal B. In addition, we can see that most people tended to publish their work in Journal B, as Journal B has larger radius compared to Journal A.

\subsubsection{Observations of Overall Journal Publication}

There were total of 378 papers published in 189 different journals in MISU. Due to space constraints, we only show the top 13 published journal titles in MISU in Table 3. As we can observe from this table, the top five publishing journals were: 1) 28 papers (7.4\%) of papers published in the International Journal of Information Management (IJIM); 2) 19 papers (5\%) of papers published in Decision Support Systems (DSS); 3) 14 papers (3.7\%) published in Expert Systems with Applications (ESA); 4) 10 papers (2.6\%) published in Telematics and Informatics (TAI); 5) 9 papers (2.4\%) published in Journal of Medical Systems (JMS), 9 papers (2.4\%) published in Information \& Management (IM), and 9 papers (2.4\%) published in Clinical EEG \& Neuroscience (CEN).

Table 3. Top 13 published journal titles in MISU

\begin{tabular}{llll}
\hline Rank & Acronyms & Journal Title & Count \\
\hline 1 & JIM & Journal of Information Management & 28 \\
2 & DSS & Decision Support Systems & 19 \\
3 & ESA & Expert Systems with Applications & 14 \\
4 & TAI & Telematics and Informatics & 10 \\
5 & JMS & Journal of Medical Systems & 9 \\
5 & IM & Information \& Management & 9 \\
5 & CEN & Clinical EEG and Neuroscience & 9 \\
8 & OIR & Online Information Review & 7 \\
9 & ECRA & Electronic Commerce Research and Applications & 6 \\
9 & IJIM & International Journal of Information Management & 6 \\
9 & CHB & Computers in Human Behavior & 6 \\
12 & JGIM & Journal of Global Information Management & 5 \\
12 & IJNS & International Journal of Neural Systems & 5 \\
\hline
\end{tabular}

\subsubsection{Observations of Overall Publications from MOST and A Lists}

There were total of 55 different journal titles from both the MOST and A-lists. Among these 55 different journal titles, MISU faculty published a total of 73 papers $(19.3 \%)$ in 17 different journals, all of which are shown with publication counts in Table 4. The top five published journals were: 1) 19 papers (26\%) published in Decision Support Systems (DSS); 2) 10 (13.7\%) papers published in Telematics and Informatics (TAI); 3) 9 papers $(12.3 \%)$ published in Information \& Management (IM); 4) 6 papers (8.2\%) published in International Journal of Information Management (IJIM), and 6 papers (8.2\%) published in Electronic Commerce Research and Applications (ECRA). Based on the statistics results shown in this table, we concluded that the publication strategies of MIS faculty were highly related with the MOST and A-lists.

Table 4. All 17 published journals in MOST and A-list

\begin{tabular}{llll}
\hline Rank & Acronyms & Journal Title & Count \\
\hline 1 & DSS & Decision Support Systems & 19 \\
2 & TAI & Telematics and Informatics & 10 \\
3 & IM & Information \& Management & 9 \\
4 & IJIM & International Journal of Information Management & 6 \\
4 & ECRA & Electronic Commerce Research and Applications & 6 \\
6 & JGIM & Journal of Global Information Management & 5 \\
7 & IJHCS & International Journal of Human-Computer Studies & 3 \\
8 & IJEC & International Journal of Electronic Commerce & 2 \\
8 & JASICT & Journal of the American Society for Info Science and Tech & 2 \\
8 & JSS & Journal of Systems and Software & 2 \\
8 & IS & Information Systems & 2 \\
\hline
\end{tabular}




\begin{tabular}{lllc}
\hline 16 & ITP & Information Technology and People & 2 \\
12 & CAIS & Communications of the AIS & 1 \\
12 & ITM & Information Technology and Management & 1 \\
12 & EM & Electronic Markets & 1 \\
16 & DAIS & The Data Base for Advances in Information Systems & 1 \\
12 & JDM & Journal of Database Management & 1 \\
\hline
\end{tabular}

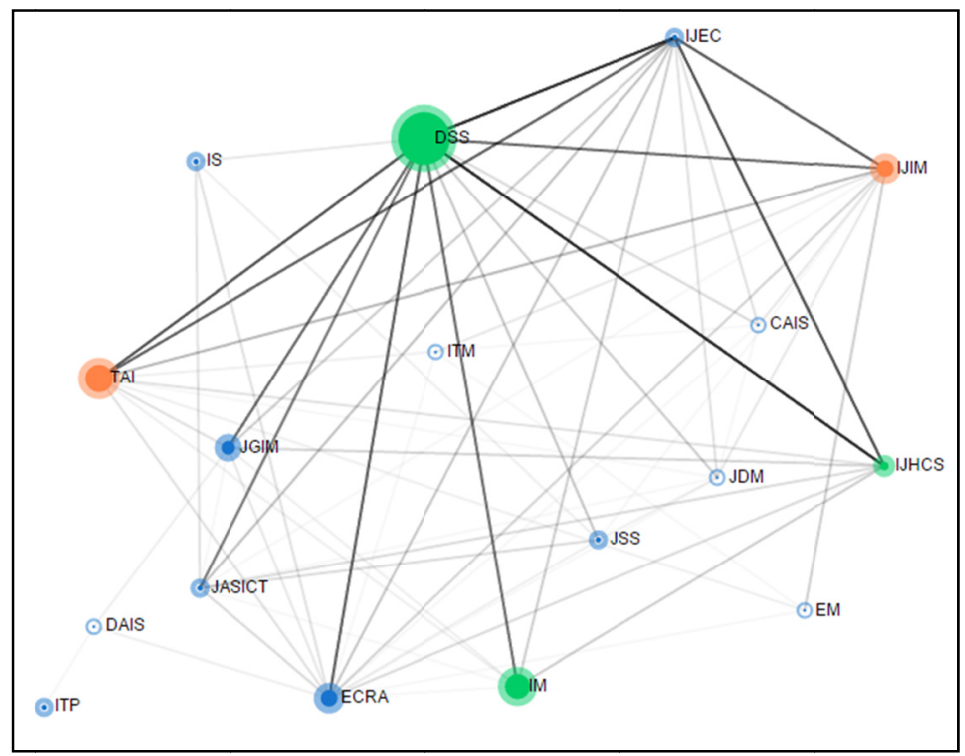

Figure 12. Overall journal publication of MISU

Figure 12 shows the overall journal publications of MISU. The blue color indicates the journal titles recommended from the MOST list, the orange color indicates the journal titles recommended from the A-list, and green color indicates the journal titles from both MOST and A-lists. In this figure, we noticed that DSS, IM, and IJHCS were in both MOST and A-lists. Next, we saw that DSS, TAI, IM, IJIM, ECRA, and JGIM all had radii larger than others, meaning that more people tended to publish their work in these journals. In addition, we saw that there were thicker edges between DSS and IJEC, DSS and IJIM, DSS and IJHCS, DSS and IM, DSS and ECRA, DSS and JASICT, DSS and JGIM, and DSS and TAI, which means there were several faculty members who published their work in DSS and also published their work in IJEC, IJIM, IJHCS, IM, ECRA, JASICT, JGIM, and TAI. Similarly, there were some thicker lines between IJEC and DSS, IJCS and TAI, IJEC and IJHCS, IJEC and IJIM, which means there were several faculty members who published their works in IJEC and also published their work in DSS, TAI, IJHCS, and IJIM. Likewise, there were some thicker lines between IJIM and IJEC, IJIM and DSS, and IJIM and TAI, where it means that there were several faculty members who published their works in IJIM and also published their works at IJEC, DSS, and TAI. Therefore, based on these observations, we can conclude that the following journals were closely related: DSS, IJEC, IJIM, IJHCS, IM ECRA, JASICT, JGIM, and TAI.

\subsection{Evolution of Faculty Collaboration and Research Productivity}

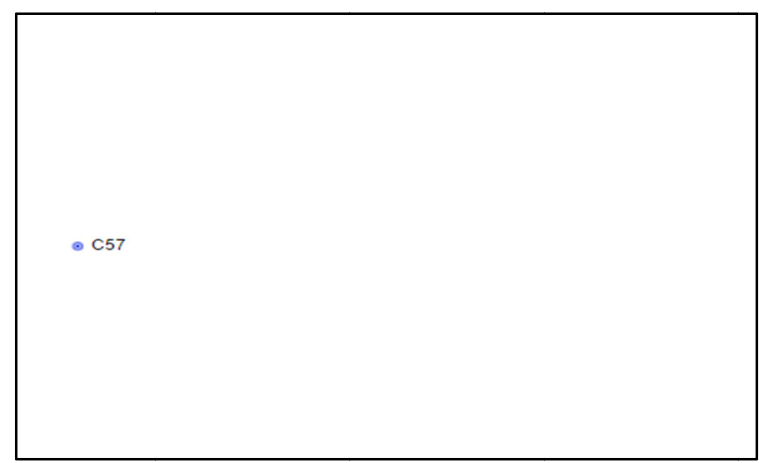

Figure 13. Collaboration \& productivity 1992 - 1995

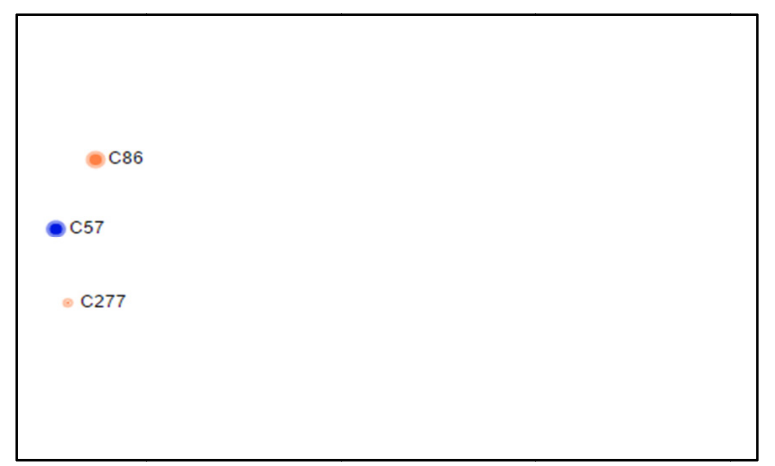

Figure 14. Collaboration \& productivity $1996-1998$ 


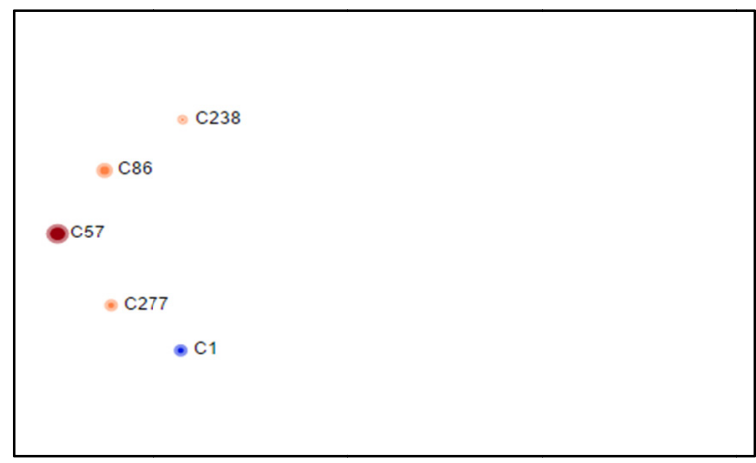

Figure 15. Collaboration \& productivity $1999-2001$

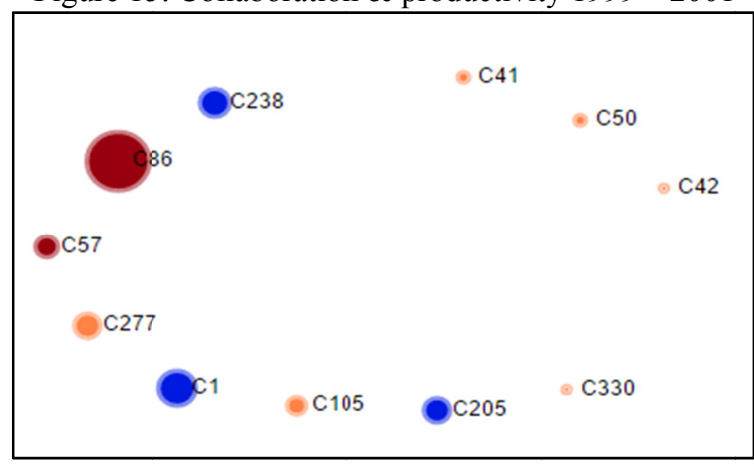

Figure 17. Collaboration \& productivity $2005-2007$

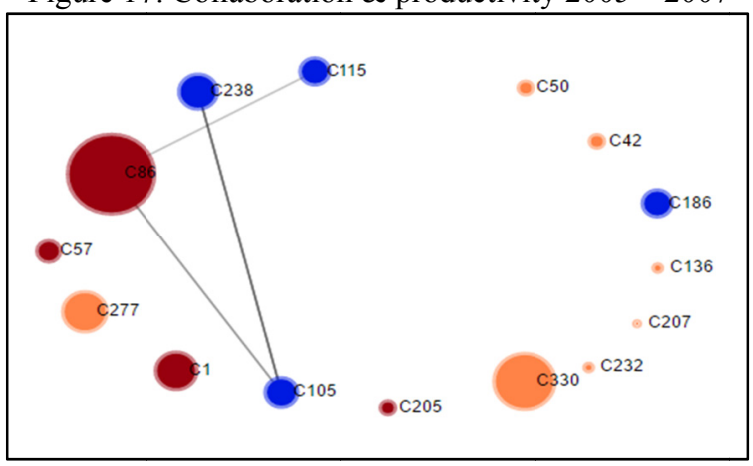

Figure 19. Collaboration \& productivity $2010-2013$

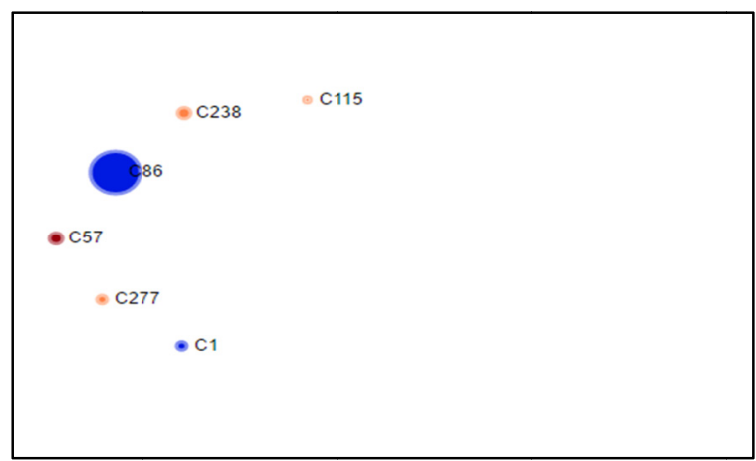

Figure 16. Collaboration \& productivity $2002-2004$

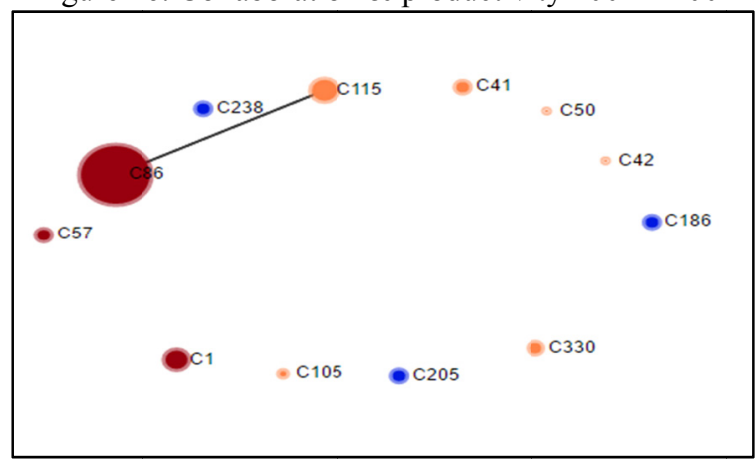

Figure 18. Collaboration \& productivity $2008-2010$

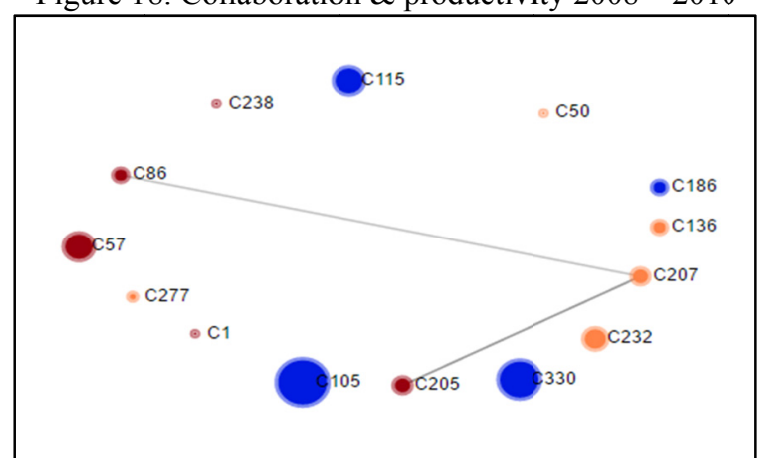

Figure 20. Collaboration \& productivity $2014-2016$

Figure 13-20 show the evolution of MISU faculty collaboration and productivity from 1992 to 2016, where each figure represents the faculty collaboration and productivity in every three years. The red color indicates the professors, the blue color indicates the associate professors, and the orange color indicates assistant professors. The lines represented the collaboration between faculty members, as the thicker lines mean more collaboration between two professors. On the other hand, the width of the node presents the total count of publications by a faculty member, with a bigger node indicating more publications. From these figures, we observed the following facts:

1) The journal publication have tended to increase over time.

2) The professor who was about to promote from assistant professor to associate professor, or from associate professor to professor, would have a significant increment on his/her publications.

3) Some professors had slightly decreased his/her publication after he/she had successfully promoted to professor.

4) The MOE introduced two university programs and an evaluation policy had influenced the MIS faculty to change their productivity and publication strategies since 2005 , such as most professors had continued to increase their publications over time, and had more collaboration after 2005.

5) Some faculty might change their collaboration patterns with respect to their academic position.

6) Assistant and associate professors tend to place more emphasis on publishing both "quantity" and "quality" papers for faculty advancement, while professors tended to emphasize only publishing more "quality" papers. 
Figure 21 shows the overall faculty collaboration and productivity in MISU from 1992 to 2016 . The width of a node represents the total publications of a faculty member, and the width of a line between two nodes represents the total publications between two faculty members. From this figure, we noticed the following:

1) Professors and associate professors tend to have most publications and collaborations.

2) Some professors had indirect collaborations with other professors (e.g., C86 had indirect collaboration with C238 and C205, because C86 had collaborations with C105, and C105 had collaborations with C238; similarly, C86 had collaborations with C207, and C207 had collaborations with C205).

3) Not all senior faculty would collaborate with other junior faculty, as some senior faculty prefer to conduct research alone.

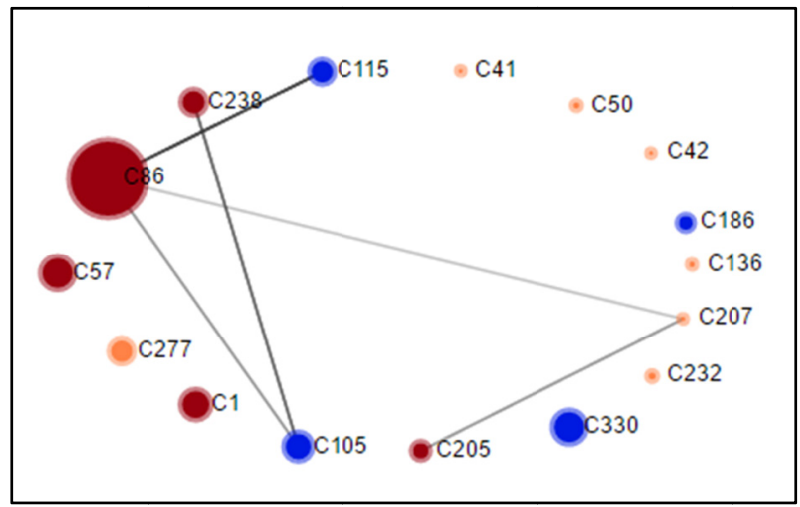

Figure 21. Overall faculty collaboration and productivity from 1992 to 2016

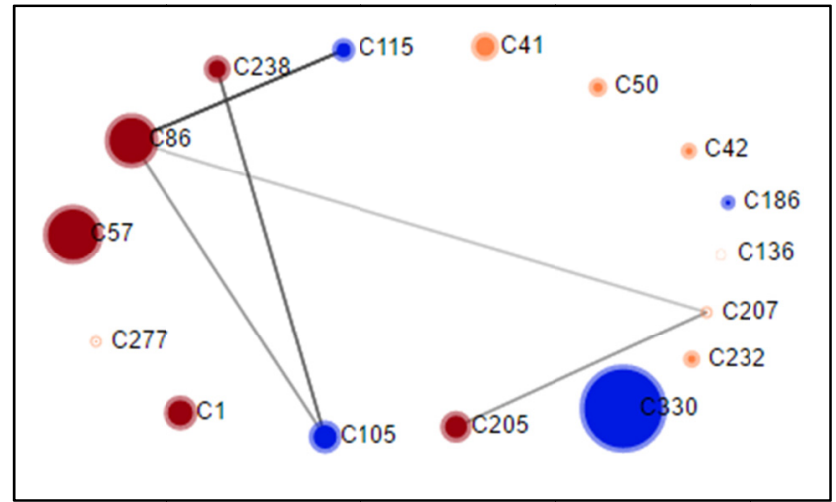

Figure 22. Overall faculty collaboration and productivity using EWMA from 1992 to 2016

Figure 22 shows the overall faculty collaboration and productivity from 1992 to 2016 using EWMA. The width of a node represents the overall contribution score of a faculty member using EWMA, and the width of a line between two nodes represents the collaboration between two faculty members using EWMA, as the EWMA calculation was described in Section 3.3.2. From this figure, we noticed the following:

1) Comparing to Figure 21, we observed that the width of some professors were significantly increased in Figure 22, and the reason was due to that these professors tended to publish journals in very high rank as first author in recent years, or vice versa. Other professors had about the same width between these two figures indicate that they were all consistently using same publication strategies from time to time.

2) Comparing to Figure 21, we noticed that the width of some professors were greatly increased in Figure 22, and the reason was because these professors published more papers in recent periods, or vice versa. Other professors had about the same width between these two figures means that they were all consistently publishing articles from time to time.

\section{Discussions \& Conclusions}

Research productivity has been always an important part of a faculty member's job description, since it has a great effect on faculty promotion and tenure decisions. In addition, some scholars believe that co-authorship between faculty members has a great impact on their academic life and faculty advancement. Since 2005, the MOE has developed two university programs and an evaluation policy to improve the competitiveness and 
internationalization of Taiwan universities, and has clearly stated the strong relationship between faculty promotion and research performance. Since them, MOST and some universities have developed recommended journal lists to help their faculty members get more research funding. Even though several papers have addressed research productivity or co-authorship, none of them has used social network analysis (SNA) to examine research productivity and co-authorship under two university programs and the evaluation policy from the MOE in Taiwan. Therefore, in this study, we first used SNA to analyze the research productivity, collaboration patterns, and publication strategies from a Management Information Systems (MIS) department at a national university in Taiwan. Then, we used D3 to visualize and discuss how these two university programs and the evaluation policy from the MOE affected these patterns and strategies. We hope that our study not only provides beneficial information to the MIS department, but can be treated as an important source for MOE committees in their future adjustment of university programs and evaluation policies.

We analyzed and visualized the following four areas using D3: 1) faculty collaboration; 2) faculty productivity; 3 ) journal publication pattern; 4) evolution of faculty collaboration and productivity. First, when we drew the degree of centrality of MISU, we discovered that except for a few assistant professors, most of MISU professor had direct or indirect collaboration with other MISU professors. In other words, we can confirm that the two university programs and evaluation policy from MOE affected most MIS faculty to tend to publish co-authored papers. Second, we had demonstrated important professors who acted as an "important bridge" in this MISU network via betweenness centrality of MISU, and noticed that not all of the professors acting as an "important bridge" were actually from MISU network. Third, when we analyzed the closeness centrality of MISU, we observed that there were the MISU professors who had greater radii were placed more toward to the center of the MISU network, and this indicated that these professors had a greater chance to influence others in the network. Fourth, we discovered that faculty collaboration follows power-law degree distribution. Fifth, we noticed that most of the faculty tended to collaborate with other professors within the same country. Lastly, we noticed that even though MISU faculty only collaborated with a few professors from other countries, these professors from other countries still played important roles in the MISU network.

Next, we analyzed MISU faculty productivity, and observed that professors with high contribution scores have the following characteristics: 1) they tended to publish their papers as first author; 2) they tended to publish high quantities of papers per year; and 3) they tended to publish their papers in the high-ranked journals.

When considering faculty publication patterns, we analyzed total of 378 papers from 189 different journals, and noticed the majority of the journal papers were published in International Journal of Information Management, Decision Support Systems, Expert Systems with Applications, Telematics and Informatics, Journal of Medical Systems, Information \& Management, and Clinical EEG \& Neuroscience. Among these popular journals, we discovered that International Journal of Information Management, Decision Support Systems, Telematics and Informatics, Information \& Management were the recommended journals from either MOST or A-lists. Therefore, we can conclude that MISU faculty publication strategies were closely related to the MOST and A-lists.

Moreover, we presented the evolution of MISU faculty collaboration and productivity from 1992 to 2016, and noticed the following: 1) most of the MISU professors had continuously published articles from time to time; 2) associate professors and assistant professors tend to focus on publishing high "quantity" and "quality" papers in order to get ready for their promotions, while professors tend to place more emphasis on only publishing "high quality" papers; 3) journal publications have tended to increase over time; 4) when a professor was prepared to promote from assistant professor to associate professor, or to promote from associate professor to professor, he/she had would have a significant increment on his/her publications at that time; 5) some professors had slightly decreased his/her publication after he/she had successfully promoted to professor; 6) The MOE introduced two university programs and an evaluation policy had influenced the MIS faculty to change their productivity and publication strategies, such as majority of professors had continued to increase their publications and collaboration since 2005 ; 7) the faculty might change their collaboration patterns with respect to their academic position.

Furthermore, we evaluated the overall evolution of faculty collaboration and productivity in MISU from 1992 to 2016, and noticed that: 1) professors and associate professors tend to have most publications and collaborations; 2) some professors had indirect collaboration with other professors; 3) not all senior faculty would collaborate with other junior faculty. We further analyzed overall faculty collaboration and research productivity from 1992 to 2016 using EWMA, and discovered that: 1) the width of some professors were significantly increased in Figure 22 because these professors tended to publish journals in very high rank as first author in recent years, or vice versa; 2) the width of some professors were greatly increased in Figure 22 because these professors tended 
to publish more papers in more recent periods but not earlier periods, or vice versa.

\section{Limitations and Future Research}

Even though the research has reached its aims, there were still some limitations in this study. Some of the main limitations to be noted:

- We only analyzed the patterns of faculty collaboration and research productivity in an MIS Department at a national university in Taiwan.

- The data drawn from the MOST website were all manually entered by each faculty member, and therefore, there might have been some missing data (e.g., Professor A published Article 1 and Article 2, but only listed Article 1).

- The data drawn from the MOST website were all manually entered by each faculty member, and therefore, there might have been some mistyped data preventing the identification of faculty collaboration (e.g., Professor A published Article 1 with Professor B, but mistyped Professor B's name, and Professor B's records were unavailable from the MOST website).

- We only analyzed faculty collaboration and research productivity based on the journal titles that belong to: 1) Science Citation Index (SCI), 2) Science Citation Index Expanded (SCIE), 3) Social Science Citation Index (SSCI), and 4) Taiwan Social Science Citation Index (TSSCI).

- All of the registered faculty members from the MOST website had both Chinese and corresponding English names. However, some co-authors (e.g. the faculty or PhD students who did not have MOST accounts) might not have included corresponding English names; for this reason, we referred to the ScienceDirect website to retrieve missing English names.

In the future, we plan to conduct an even bigger analysis, collecting all of the publication data among all MIS departments from all the universities in Taiwan. After having all the data processed, we plan to use SNA to visualize and discuss how the two university programs and the evaluation policy from the MOE affect faculty collaboration, research productivity, and publication strategies across all the MIS departments in Taiwan.

\section{Acknowledgments}

This research was supported in part by MOST 104-2410-H-194-090-MY2 of the Ministry of Science and Technology, Taiwan.

\section{References}

Albrecht, S., Wilks, T. J., \& Wood, D. A. (2015). Measuring the impact of faculty research: A case study. Available at SSRN 2602466. http://dx.doi.org/10.2139/ssrn.2602466

Benckendorff, P., \& Zehrer, A. (2014). Career and collaboration patterns in tourism research. Current Issues in Tourism, 19(14), 1386-1404. http://dx.doi.org/10.1080/13683500.2014.896320

Bobstock, M. (2016). Retrieved June 2, 2016, from http://bost.ocks.org/mike/

Bonzi, S. (1992). Trends in research productivity among senior faculty. Information Processing \& Management, 28(1), 111-120. http://dx.doi.org/10.1016/0306-4573(92)90097-J

Bozeman, B., Gaughan, M., Youtie, J., Slade, C. P., \& Rimes, H. (2015). Research collaboration experiences, good and bad: Dispatches from the front lines. Science and Public Policy, 43(2), 226-244. http://dx.doi.org/10.1093/scipol/scv035

Burt, R. S., Kilduff, M., \& Tasselli, S. (2013). Social network analysis: Foundations and frontiers on advantage. Annual review of psychology, 64, 527-547. http://dx.doi.org/10.1146/annurev-psych-113011-143828

Chen, Y., \& Liu, Z. (2005). The rise of mapping knowledge domain. Studies in Science of Science, 23(2), 149-154.

Chou, C. (2014). Analysis of Academic Research Evaluation Indicators of Taiwan's Humanities and Social Sciences. Journal of Education of Taipei Municipal University of Education, (47), 1-19.

D3 (2016), Retrieved June 2, 2016, from http://d3js.org

Fox, M. F., \& Faver, C. A. (1984). Independence and cooperation in research: The motivations and costs of collaboration. The Journal of Higher Education, 55(3), 347-359. http://dx.doi.org/10.2307/1981888

Gallivan, M., \& Ahuja, M. (2015). Co-authorship, homophily, and scholarly influence in information systems research. Journal of the Association for Information Systems, 16(12), 980. 
Hadjinicola, G. C., \& Soteriou, A. C. (2006). Factors affecting research productivity of production and operations management groups: An empirical study. Journal of Applied Mathematics and Decision Sciences, 2006. http://dx.doi.org/10.1155/JAMDS/2006/96542

Horta, H., \& Jung, J. (2014). Higher education research in Asia: an archipelago, two continents or merely atomization? Higher Education, 68(1), 117-134. http://dx.doi.org/10.1007/s10734-013-9695-8

Jeong, H., Tombor, B., Albert, R., Oltvai, Z. N., \& Barabasi, A.-L. (2000). The large-scale organization of metabolic networks. Nature, 407(6804), 651-654.

Jeong, H., Mason, S. P., Barabasi, A.-L., \& Oltvai, Z. N. (2001). Lethality and centrality in protein networks. Nature, 411(6833), 41-42.

Jones, J. E., Preusz, G. C., \& Finkelstein, S. N. (1989). Factors associated with clinical dental faculty research productivity. Journal of dental education, 53(11), 638-645.

Kennedy, D. (2003). Multiple authors, multiple problems. Science, 301(5634), 733. http://dx.doi.org/10.1126/science.301.5634.733

Lai, H., Hwang, S., Liang, T., Hung, S., \& Wu, H. (2011) Journal Publications of MIS Departments in Taiwan. Journal of Information Management, 8(3), 175-196.

Li, E. Y., Liao, C. H., \& Yen, H. R. (2013). Co-authorship networks and research impact: A social capital perspective. Research Policy, 42(9), 1515-1530. http://dx.doi.org/10.1016/j.respol.2013.06.012

Liang, T. P. (2013) Quality Analysis of International Academic Journal in MOST Management II Discipline. Humanities and Social Sciences Newsletter Quarterly, 14(2), 109-122. Retrieved February 8, 2017, from https://www.most.gov.tw/most/attachments/80726aa1-1f52-48af-a320-372e965e909f

Liu, Z., Yin, Y., Liu, W., \& Dunford, M. (2015). Visualizing the intellectual structure and evolution of innovation systems research: a bibliometric analysis. Scientometrics, 103(1), 135-158. http://dx.doi.org/10.1007/s11192-014-1517-y

Mascolo, C. (2012). Lecture 3: Centrality Measures [Powerpoint slides]. Retrieved on Feb 8, 2017, from https://www.cl.cam.ac.uk/teaching/1213/L109/stna-lecture3.pdf

Mattsson, P., Sundberg, C. J., \& Laget, P. (2011). Is correspondence reflected in the author position? A bibliometric study of the relation between corresponding author and byline position. Scientometrics, 87(1), 99-105. DOI 10.1007/s11192-010-0310-9

McAndrew, S., \& Everett, M. (2015). Music as collective invention: A social network analysis of composers. Cultural Sociology, 9(1), 56-80. http://dx.doi.org/10.1177/1749975514542486

Mena-Chalco, J. P., Digiampietri, L. A., Lopes, F. M., \& Cesar, R. M. (2014). Brazilian bibliometric coauthorship networks. Journal of the Association for Information Science and Technology, 65(7), 1424-1445. http://dx.doi.org/10.1002/asi.23010

Newman, M. E. (2004). Coauthorship networks and patterns of scientific collaboration. Proceedings of the national academy of sciences, 101(suppl 1), 5200-5205. http://dx.doi.org/10.1073/pnas.0307545100

Reisenberg, D., \& Lundberg, G. D. (1990). The order of authorship: Who's on first? JAMA, 264(14), 1857.

Rennie, D., Yank, V., \& Emanuel, L. (1997). When authorship fails-a proposal to make contributors accountable. JAMA, 278(7), 579-585.

Salthouse, T. A., Mckeachie, W. J., \& Lin, Y.-G. (1978). An experimental investigation of factors affecting university promotion decision: A brief report. The Journal of Higher Education, 49(2), 177-183. http://dx.doi.org/10.2307/1979282

Scott, J. (2002). Social networks: Critical concepts in sociology (Vol. 4). Taylor \& Francis.

Scott, J. (2012). Social network analysis. Sage.

Sud, P., \& Thelwall, M. (2016). Not all international collaboration is beneficial: The Mendeley readership and citation impact of biochemical research collaboration. Journal of the Association for Information Science and Technology, 67(8), 1849-1857, http://dx.doi.org/10.1002/asi.23515

Tsai, C.-C., Corley, E. A., \& Bozeman, B. (2016). Collaboration experiences across scientific disciplines and cohorts. Scientometrics, 108(2), 505-529. http://dx.doi.org/10.1007/s11192-016-1997-z

Ware, C. (2012). Information visualization: perception for design. Elsevier. 
Wardil, L., \& Hauert, C. (2015). Cooperation and coauthorship in scientific publishing. Physical Review E, 91(1), 012825. http://dx.doi.org/10.1103/PhysRevE.91.012825

Wasserman, S., \& Faust, K. (1994). Social network analysis: Methods and applications (Vol. 8): Cambridge University Press.

Xiao, M., Qiu, X., Huang, J., Li, G., \& Feng, Z. (2013). Comparison of Software Tools for Mapping Knowledge Domain. Library Journal, 32(3), 61-69.

Yoon, B., Lee, S., \& Lee, G. (2010). Development and application of a keyword-based knowledge map for effective R\&D planning. Scientometrics, 85(3), 803-820. http://dx.doi.org/10.1007/s11192-010-0294-5

Zhang, G., Feng, Y., Liu, L., Shao, Z., Han, Y., \& Wu, J. (2014). Understanding the Evolution of Information Systems Research from the Perspective of Co-Authorship Network: a Comprehensive Data Analysis from 1993 to 2012. Proceedings of Pacific Asia Conference on Information Systems (PACIS), Chengdu, China.

Zhang, D., Guo, Y., Zhao, Z., \& Zhou, Y. (2016). Co-authorship Networks in Additive Manufacturing Studies Based on Social Network Analysis. British Journal of Applied Science \& Technology, 15(1), 1. http://dx.doi.org/10.9734/BJAST/2016/24462

\section{Appendix 1.}

Recommended journal list from Information Science \& Library Science category of Ministry of Science and Technology of Taiwan (MOST).

Management of Information Science Journal Ranking List

\begin{tabular}{|c|c|}
\hline Rank & Journal Title \\
\hline 1 & MIS Quarterly \\
\hline 2 & Information Systems Research \\
\hline 3 & Journal of Management Information Systems \\
\hline 4 & Journal of the AIS \\
\hline 5 & Decision Sciences \\
\hline 6 & Decision Support Systems \\
\hline 7 & Information and Management \\
\hline 8 & European Journal of Information Systems \\
\hline 9 & Human-Computer Interaction \\
\hline 10 & Information System Journal \\
\hline 11 & Journal of Strategic Information Systems \\
\hline 12 & International Journal of Electronic Commerce \\
\hline 13 & International Journal of Human-Computer Studies \\
\hline 14 & Journal of Information Technology \\
\hline 15 & Communications of AIS \\
\hline 16 & Information System Frontier \\
\hline 17 & The Data Base for Advances in Information Systems \\
\hline 18 & Journal of Global Information Management \\
\hline 19 & Information \& Organization \\
\hline 20 & Journal of Organizational Computing and Electronic Commerce \\
\hline 21 & Information Technology and People \\
\hline 22 & Information Technology and Management \\
\hline 23 & The Information Society \\
\hline 24 & Journal of Global Information Technology Management \\
\hline 25 & Electronic Markets \\
\hline 26 & Information Resources Management Journal \\
\hline 27 & Journal of Information Technology Theory and Application \\
\hline 28 & Electronic Commerce Research and Applications \\
\hline 29 & Information Systems Management \\
\hline 30 & Journal of Organizational and End User Computing \\
\hline
\end{tabular}


Information Technology-Oriented Journal Ranking List

\begin{tabular}{ll}
\hline Rank & Journal Title \\
\hline 1 & IEEE Transactions on Knowledge and Data Engineering \\
2 & IEEE Transactions on Software Engineering \\
3 & Artificial Intelligence \\
4 & IEEE Transactions on System, Man, and Cybernetics \\
5 & IEEE Transactions on Computers \\
6 & ACM Transactions on Information Systems \\
7 & ACM Transactions on Database Systems \\
8 & INFORMS Journal on Computing \\
9 & Information Systems \\
10 & Journal of Database Management \\
11 & Information Processing and Management \\
12 & IEEE-ACM Transactions on Networking \\
13 & Journal of Systems and Software \\
14 & Journal of the American Society for Information Science and Technology \\
15 & Computer Journal \\
\hline
\end{tabular}

\section{Appendix 2.}

Recommended journal list from MISU for faculty promotion purposes (Sorted alphabetically)

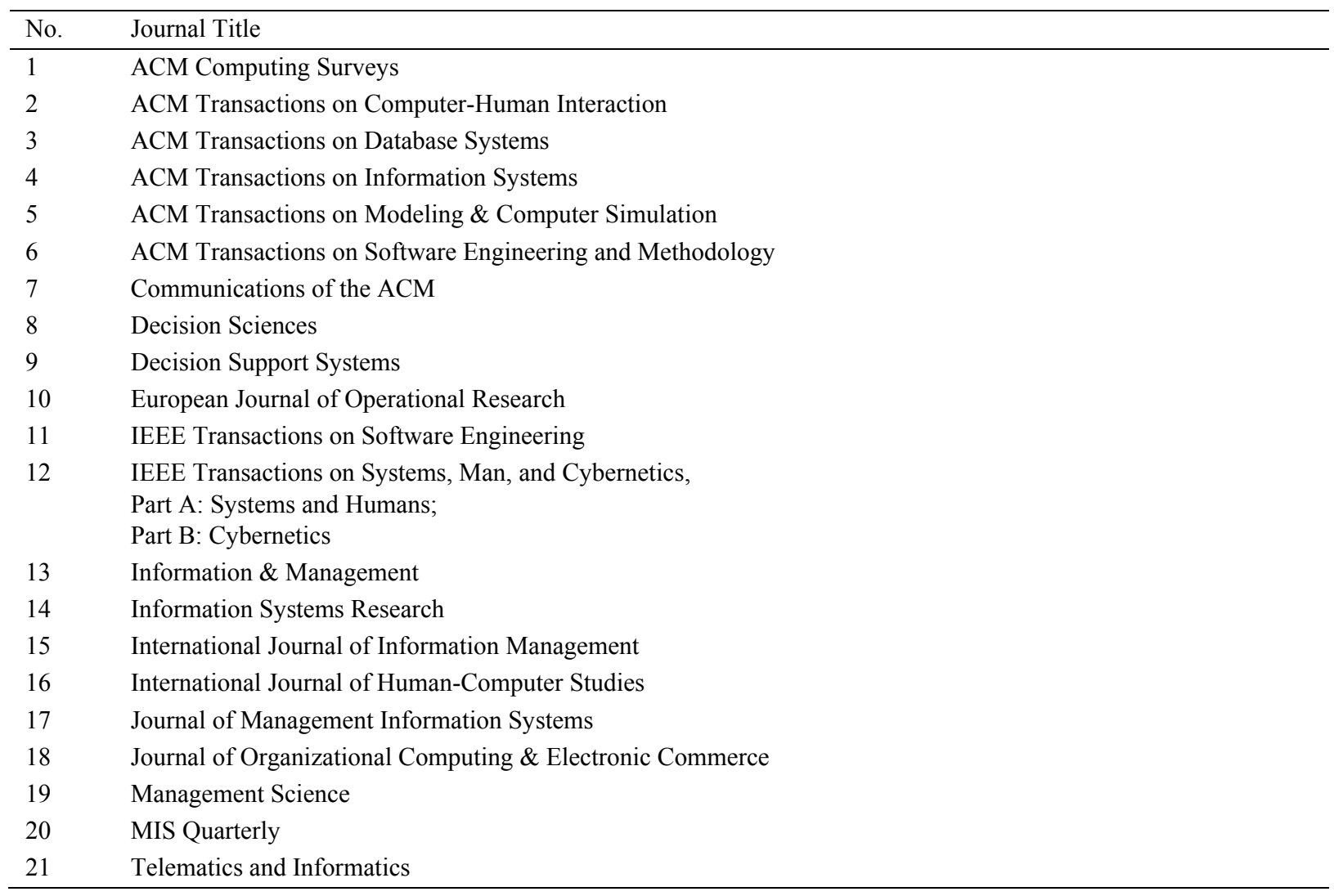

\section{Copyrights}

Copyright for this article is retained by the author(s), with first publication rights granted to the journal.

This is an open-access article distributed under the terms and conditions of the Creative Commons Attribution license (http://creativecommons.org/licenses/by/4.0/). 